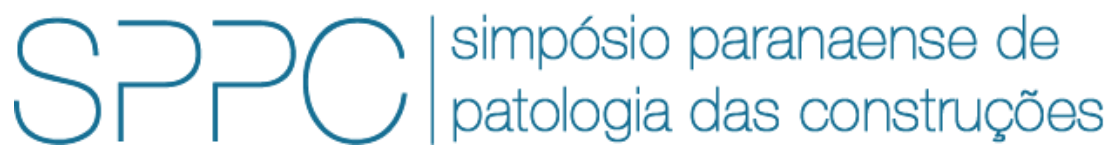

ISSN 2526-7248 artigo 2SPPC2002 pp. 474-485, 2017

\title{
Análise da cravabilidade de estacas através de simulações computacionais com uso da teoria da propagação da onda
}

\author{
Gislaine Klenk¹, Dr. Luiz Russo Neto² \\ ${ }_{1}^{1}$ Mestranda, Universidade Federal do Paraná, gislaineklenk@hotmail.com \\ 2 Professor, Pontifícia Universidade Católica do Paraná, luiz.russo@pucpr.br
}

Resumo: A maioria das manifestações patológicas ocorrem devido à deficiência de projetos ou má execução das obras. Problemas como fissuras e trincas, podem ter sua origem relacionada à defeitos na fundação. Assim, este estudo objetiva a otimização do sistema de cravação de estacas prémoldadas de concreto, através da determinação do menor número de golpes totais sem promover a quebra da estaca, sob a ótica do módulo de elasticidade do coxim. O sistema de cravação por percussão de bate-estacas em queda livre, é um dos métodos mais utilizados no Brasil. O processo de cravação pode ser modelado pela teoria da propagação da onda. Com a adaptação deste método para ferramentas computacionais, como o GRLWEAP, é possível simular e selecionar o sistema de cravação adequado para cada situação. Assim, foram analisados os relatórios das simulações, variando o módulo de elasticidade do coxim de $200 \mathrm{~mm}$ (Madeirit e Jatobá), alturas de queda e pesos do martelo $(10,20$ e $30 \mathrm{kN})$. Foi utilizado estaca de seção 30 por $30 \mathrm{~cm}$, comprimento de $10 \mathrm{~m}$, capacidade de carga de $1.080 \mathrm{kN}$ e $50 \%$ de resistência de ponta e lateral. Observou-se que, com a mesma energia, martelos mais pesados com alturas de queda menores são mais eficientes, pois geram um menor número de golpes, menores tensões de compressão e tração, além de maior eficiência do conjunto. O coxim de Jatobá conduz a um menor espectro de energia, pois ocorre a quebra da estaca com mais facilidade e para alturas de queda inferiores ao de Madeirit.

Palavras-chave: Cravabilidade. Estacas pré-moldadas. Sistema de amortecimento.

Abstract: Most of the pathological manifestation occur due to deficiency of projects or poor execution. Problems such as fissures and cracks may have their origin related to foundation failure. Thus, this study aims to optimize the precast concrete piles driving system, through the smaller number of blows without promoting the pile's breakdown, under de perspective of the elasticity modulus of the cushion. The freefall pile driving is one of the widely used methods in Brazil. The pile driving process can be modeled by the wave propagations theory. With the adaptation of this method for computational tools, such as GRLWEAP, it is possible to simulate and select the pile driving system appropriate for each situation. Thus, simulations were analyzed varying the elasticity modulus of the cushion of $200 \mathrm{~mm}$ (Madeirit and Jatoba), drop heights and weights of the hammer. A pile with a section of $30 \times 30 \mathrm{~cm}, 10 \mathrm{~m}$ length, $1.080 \mathrm{kN}$ load capacity, and $50 \%$ shaft friction, was used in the analysis. Is was observed that, with the same energy, heavy hammers smaller drop heights are more effective because they generate a smaller number of blow, lower tension compression and traction, as well greater efficiency of the set. The Jatoba cushion leads to a lower energy spectrum, because the piles breaks more easily and also to drop heights below the Madeirit.

Keywords: Drivability. Precast concrete pile. Dampyng system. 


\section{Introdução}

Segundo Silva [1], a patologia das construções é uma ciência que estuda os sintomas, os mecanismos, as causas e origens dos defeitos nas construções. Estes problemas podem ser adquiridos na concepção (planejamento, projeto e materiais), execução ou utilização da obra.

É ideal que seja feito a profilaxia nas construções, ou seja, aplicação de meios para evitar as "doenças" dos edifícios, bem como suas propagações. Caso ocorram danos, é necessário realizar o prognóstico da situação, que é a estimativa da evolução do problema ao longo do tempo [1]. Em geral, as perdas financeiras ocasionadas pelos processos de degradação das estruturas são elevadas.

A maior parte das manifestações patológicas têm sua origem na deficiência de projetos ou na má execução das obras. Pode-se associar à qualidade de execução, alguns fatores como a qualidade no gerenciamento da obra, no recebimento dos materiais e de equipamentos e, principalmente, da execução dos serviços propriamente dita.

Manifestações patológicas, como fissuras e trincas, podem ter sua origem relacionada à defeitos na fundação. Uma das técnicas construtivas mais utilizada no Brasil para fundações profundas, é o método de cravação por percussão do "tipo queda livre", que envolve a inserção do elemento estrutural no maciço de solo por meio de equipamentos específicos, denominados sistemas de cravação.

No processo de cravação de estacas, ocorrem com muita frequência casos de insucesso ou de mau uso dessa técnica de engenharia, como a quebra da estaca durante o processo executivo, ruídos, vibrações ou a estaca não atinge a profundidade solicitada no projeto. Segundo Gonçalves et al. [2], "pode-se afirmar que o maior índice de quebras de estacas está associado ao sistema de cravação ou aos acessórios utilizados [...] como capacetes metálicos, suplementos, cepos e coxins de madeira". Para minimizar tais problemas, mostra-se a importância do estudo do sistema de cravação, para a escolha ideal do conjunto bate-estacas e sistema de amortecimento a ser utilizado.

A boa performance de um sistema de cravação como este, encontra-se dependente das condições de manutenção e de ajuste de todas as peças que o compõem, pois as perdas de energia envolvidas no sistema podem ser expressivas. Em geral, tal sistema de cravação apresenta eficiência (Erea/ $/ E_{\text {pot}}$ ) entre 40 e $60 \%$, podendo apresentar valores sensivelmente superiores em alguns casos específicos, segundo Gonçalves et al. [3].

Para que ocorra a distribuição uniforme das tensões dinâmicas que surgem devido aos impactos do martelo sobre a cabeça das estacas, é instalado entre o martelo e o topo da estaca, um capacete metálico. O capacete é composto na sua parte superior por um cepo de madeira dura, sobre o qual são desferidos os golpes do martelo e sua principal função é proteger o martelo de tensões elevadas. Na parte inferior do capacete encontra-se o amortecedor, chamado de almofada ou coxim, composto de madeira mole, cujo intuito é amortecer a estaca dos golpes e das altas tensões, e assim garantir que o risco de quebras de estacas seja reduzido [2]. As dimensões desses elementos devem estar de acordo com a geometria da estaca, evitando folgas 
excessivas que possam provocar oscilações demasiadas das estacas durante a cravação e, consequentemente, possíveis danos.

Os coxins de madeira natural ou industrial geralmente são inutilizados após o uso em cada estaca cravada, não apresentando condições de reaproveitamento. Muitas vezes ocorre a incineração do coxim, principalmente quando se cravam estacas em solos muito compactos, sendo necessário a troca de coxins várias vezes no transcurso das cravações, especialmente nas estacas mais longas, onde existem vários segmentos a serem cravados. Além disso, o coxim não deve apresentar nós que possibilitem a ocorrência de propagação de tensões diferenciais em decorrência dos impactos do martelo, e apresentar uma superfície plana e nivelada em relação ao plano do topo das estacas, segundo Gonçalves et al. [2].

Portanto, neste trabalho objetiva-se analisar a influência do módulo de elasticidade do material do coxim (entre Jatobá e Madeirit) na instalação de uma estaca prémoldada no solo, através da obtenção do menor número de golpes totais sem promover a quebra da estaca, considerando a possibilidade de diferentes alturas de queda e diferentes pesos de martelo. Para tanto, será utilizado o programa GRLWEAPTM (WEAP - Wave Equation Analysis of Pile Driving), onde o processo de cravação de uma estaca é modelado pela teoria da propagação da onda.

Edward A. L. Smith ao final da década de 1940, idealizou uma solução numérica da equação da onda para prever a nega na cravação de modo mais eficiente, e de também conseguir estimar as tensões dinâmicas. Em 1960, Smith publicou um trabalho que propõe um método para a solução da equação da onda utilizando equações de propagação unidimensional de onda de tensões. Com a adaptação deste método para ferramentas computacionais, como o GRLWEAPTM , é possível simular e selecionar o tipo de sistema de cravação adequado para uma determinada situação.

Conceitualmente, a estaca é tomada como uma barra ao longo da qual uma onda, gerada pelo golpe do martelo, se propaga. Esta onda está sujeita a atenuação por ação do solo que envolve a estaca. A equação da onda considera, além das características do martelo e da estaca, os acessórios e o solo.

O programa resolve a equação unidimensional da onda, usando um modelo discreto de massas concentradas. O GRLWEAP ${ }^{T M}$ calcula os esforços dinâmicos resultantes da cravação, e relaciona a nega com a capacidade de carga da estaca. Para sua concepção, em 1988, o programa GRLWEAP ${ }^{T M}$ foi baseado no programa WEAP de 1976, segundo informações em PDI [4]. É um programa bem aceito e confiável para prever o critério de nega, bem como as tensões dinâmicas de cravação e 0 desempenho do martelo de estacas cravadas.

\section{Metodologia}

Para analisar o sistema de cravação de uma estaca, sob a perspectiva da rigidez do sistema de amortecimento coxim, foi feito o estudo dos relatórios gerados por simulações no programa GRLWEAP ${ }^{T M}$. Os dados de entrada do programa, dizem respeito as características do bate-estacas, como altura de queda, massa e eficiência; características do sistema de amortecimento: peso do capacete, espessuras de cepo e de coxim e seus respectivos módulos de elasticidade e características do solo, que 
são: distribuição de resistências estáticas limite, deslocamento elástico máximo ("quake") e constantes de amortecimento ("damping") do solo.

Como há um grande número de variáveis envolvidas, algumas delas foram mantidas constantes, a fim de delimitar o universo deste trabalho. Quanto à estaca pré-moldada de concreto (Tabela 1), esta apresenta resistência característica do concreto de 30 $\mathrm{MPa}\left(\mathrm{f}_{\mathrm{ck}}\right)$, seção transversal 30 por $30 \mathrm{~cm}$ e comprimento de $10 \mathrm{~m}$. A tensão admissível de trabalho adotada foi de $6 \mathrm{MPa}$, consequentemente obtém-se uma carga de trabalho máxima de $540 \mathrm{kN}$. A carga de ruptura considerada foi de $1.080 \mathrm{kN}$, utilizando-se o fator de segurança 2, que corresponde ao mínimo recomendado pela NBR 6122 [5]. Quanto à distribuição da resistência do solo, considerou-se $50 \%$ para a parcela lateral e $50 \%$ para a parcela de ponta.

Tabela 1: Informações da estaca

\begin{tabular}{lcc}
\hline Item & Valor & Unidade \\
\hline Seção & 900 & $\mathrm{~cm}^{2}$ \\
Comprimento & 10 & $\mathrm{~m}$ \\
Profundidade de penetração & 10 & $\mathrm{~m}$ \\
Módulo de elasticidade & 34.500 & $\mathrm{MPa}$ \\
Peso específico & 23,6 & $\mathrm{kN} / \mathrm{m}^{3}$ \\
Rigidez & 0,0 & $\mathrm{kN} / \mathrm{mm}^{2}$ \\
Área de ponta & 900 & $\mathrm{~cm}^{2}$ \\
Resistências de ponta e lateral & 50 & $\%$ \\
Perímetro & 1,2 & $\mathrm{~m}$ \\
Espessura & 300 & $\mathrm{~mm}$ \\
Coeficiente de restituição & 0,5 & $\mathrm{Não}$ aplicado \\
Material & Concreto & Não aplicado \\
\hline
\end{tabular}

Neste projeto, variou-se o peso do martelo entre 10, 20 e $30 \mathrm{kN}$ (Tabela 2). Apesar do valor do martelo de $10 \mathrm{kN}$ estar fora do intervalo recomendado pela NBR 6122 [5], ele foi utilizado somente para análise com fins acadêmicos. As alturas de queda iniciam em $0,5 \mathrm{~m}$, sendo seu limite o valor onde ocorre a quebra da estaca, com o critério de tensão máxima de compressão inferior a $25 \mathrm{MPa}$. Pela altura de queda do martelo e a massa do mesmo pode-se pré-estabelecer a energia de cravação pela expressão: $E_{p o t}=m \times g \times h$. Na escolha dos módulos de elasticidade para variar no coxim, utilizou-se Madeirit (207 MPa) e Jatobá (23.607 MPa). Estas madeiras foram escolhidas por serem bastante empregadas no Brasil, deixando assim a pesquisa mais próxima da realidade, além de permitir uma variação considerável no módulo de elasticidade, possibilitando assim uma melhor análise.

Tabela 2: Dados variáveis

\begin{tabular}{ccccc}
\hline Item & Intervalo & Período & Unidade & $\begin{array}{c}\text { Total de análises } \\
\text { por item }\end{array}$ \\
\hline $\begin{array}{c}\text { Altura de queda } \\
\text { Módulo de elasticidade }\end{array}$ & $0,5-$ variável $^{*}$ & 0,5 & $\mathrm{~m}$ & variável $^{*}$ \\
$\begin{array}{c}\text { do Coxim } \\
\text { Peso do martelo }\end{array}$ & $207-23.607$ & - & $\mathrm{MPa}$ & 2 \\
\hline
\end{tabular}


* O valor limite da altura de queda é determinado durante as simulações, quando há ruptura da estaca, ou quando o valor máximo da tensão de compressão é alcançado.

Para os parâmetros mantidos constantes no sistema de amortecimento (Tabela 3), foi adotado para o cepo e o coxim a espessura de $200 \mathrm{~mm}$, segundo Santos [6]. Na escolha do módulo de elasticidade do cepo, adotou-se o Madeirit (207 Mpa), como proposto por Paes [7] quando esta realizou o estudo do cepo.

Tabela 3: Informações do sistema de amortecimento

\begin{tabular}{lcc}
\hline Item & Valor & Unidade \\
\hline Espessura Coxim & 200 & $\mathrm{~mm}$ \\
Espessura Cepo & 200 & $\mathrm{~mm}$ \\
Módulo de elasticidade do Cepo & 207 & $\mathrm{MPa}$ \\
\hline
\end{tabular}

Os parâmetros utilizados nas simulações para representar o solo (Tabela 4) e as características do martelo usado (Tabela 5), estão apresentados abaixo.

Tabela 4: Parâmetros do solo

\begin{tabular}{lcc}
\hline Item & Quake $(\mathbf{m m})$ & Damping $(\mathbf{s} / \mathbf{m})$ \\
\hline Fuste & 2,5 & 0,65 \\
Ponta & 2,5 & 0,5 \\
\hline
\end{tabular}

Tabela 5: Informações do martelo

\begin{tabular}{lcc}
\hline Item & Valor & Unidade \\
\hline Eficiência & 60 & $\%$ \\
Coeficiente de restituição & 0,8 & Não aplicado \\
Peso & 1,0 & $\mathrm{kN}$ \\
\hline
\end{tabular}

Ao final das simulações, o programa fornece como resposta o número total de golpes necessários para a total cravação da estaca, o tempo total dispendido, a energia total empregada para a execução da tarefa, as tensões de compressão e de tração desenvolvidas, a eficiência do sistema, e os deslocamentos máximo e permanente da estaca (nega).

Após finalizadas todas as simulações, realizou-se a coleta de informações e a análise gráfica dos dados gerados, para verificar a influência do módulo de elasticidade do material do coxim (madeira de lei ou Madeirit) na instalação de uma estaca prémoldada no solo, através da obtenção do menor número de golpes totais sem promover a quebra da estaca.

\section{Resultados}

As simulações realizadas neste trabalho visam contribuir com o processo executivo de cravação de estacas pré-moldadas, de forma a minimizar os danos de execução e possíveis custos fora do escopo, originados por falhas e cravações ineficientes. Para tanto, foi analisada a melhor disposição do sistema de amortecimento, sob a 
perspectiva do módulo de elasticidade do material do coxim, de modo que o sistema apresentasse o melhor desempenho na cravação.

Foram geradas cerca de 101 simulações, entre as diferentes alturas de queda, massa dos martelos e módulos de elasticidade do sistema de amortecimento coxim. Estas simulações fornecem relatórios extensos, com informações completas de cada item. Portanto, para uma melhor visualização dos resultados, serão analisados os dados de saída do programa individualmente, todos plotados em relação a energia potencial gravitacional.

Os resultados obtidos mostram a influência que a altura de queda exerce sobre o número total de golpes necessários para a total cravação da estaca, sendo este diminuído a medida em que é aumentada a altura de queda do martelo (Fig. 1). Se confrontados os valores de diferentes pesos de martelos, observa-se que para ambas as madeiras, com $30 \mathrm{kN}$ obtém-se um menor número de golpes para a cravação da estaca. Ao comparar as curvas entre diferentes madeiras, para um mesmo peso de martelo, observa-se que a medida que se aumenta a energia potencial, os valores para o Madeirit e Jatobá ficam próximos, sendo neste último encontrados as menores quantidades de número de golpes. Portanto, para uma mesma energia o número de golpes é sempre menor para o caso em que é utilizada a madeira Jatobá, quando comparado ao uso de Madeirit.

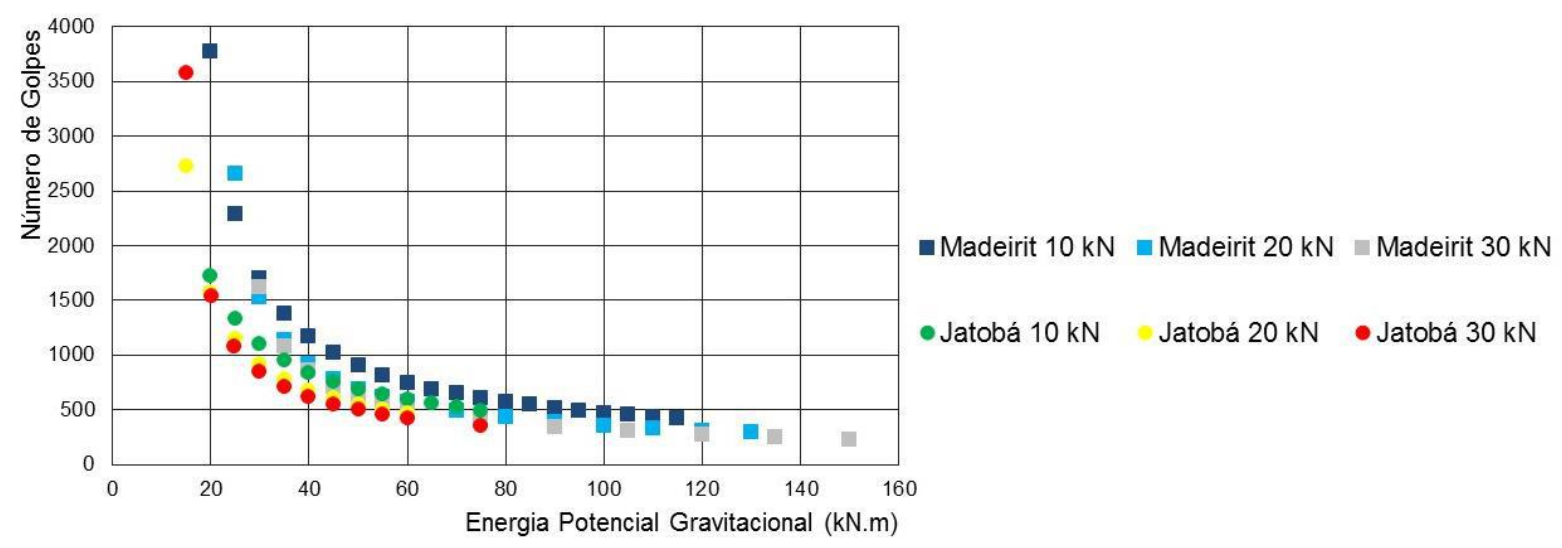

Figura 1: Número de golpes vs. Energia Potencial

A análise realizada da perspectiva das tensões máximas de tração e compressão atingidas na cravação, necessitam de especial atenção. Quanto aos resultados da máxima tensão de compressão, sabe-se que esta não deve ultrapassar $85 \%$ da resistência característica do concreto da estaca, e é gerada no momento em que o golpe é desferido na estaca. Já para tensões de tração, o concreto oferece baixa resistência, portanto as estacas feitas por este material merecem minucioso cuidado quanto à valores elevados das tensões de tração.

Quanto aos resultados, observa-se que em todos os casos a tensão de compressão é maior para o coxim de Jatobá (Fig. 2 (a)). Porém, vale destacar que para uma mesma energia potencial, as tensões de compressão das duas madeiras são próximas, sendo que a diferença se dá pela cravação com coxim de Jatobá ser em uma altura menor. Pode-se dizer que a altura de queda é diretamente proporcional a tensão máxima de compressão, pois esta aumenta à medida que aumenta a altura de queda. Em contrapartida, a massa do sistema de cravação é inversamente 
proporcional à tensão de compressão, pois a medida que se aumenta a massa do martelo, diminui-se a tensão de compressão máxima para o Madeirit, e para o Jatobá, os valores ficam muito próximos.

Já a tensão máxima de tração é comparada com a energia medida no topo da estaca, ou seja, a energia que realmente chega na estaca (Fig. 2 (b)). Percebe-se que para as duas madeiras e entre os martelos, os maiores valores de tensão máxima de tração são para o Madeirit com martelo de $10 \mathrm{kN}$. Para os dois módulos de elasticidade, os menores valores de tração são observados nos martelos de maior massa. É perceptível também, a pouca influência que a altura de queda representa para a tensão de tração máxima. Na comparação entre os dois módulos de elasticidade, o coxim de Jatobá corresponde aos menores valores.

(a) Tensão de compressão

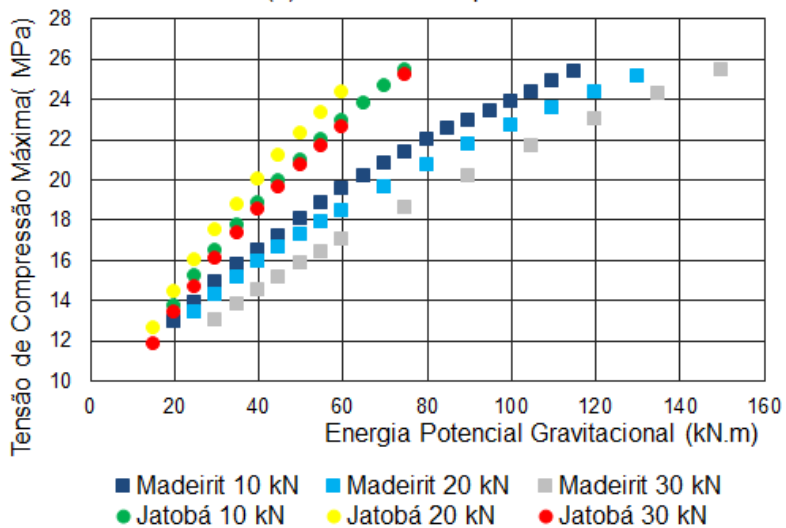

(b) Tensão de tração

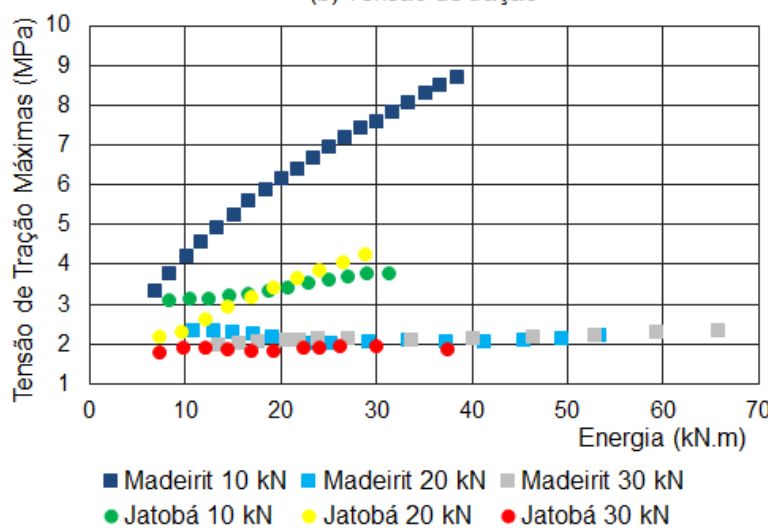

Figura 2: Tensões vs. Energia Potencial. (a) Tensão de compressão máxima.

(b) Tensão de tração máxima

Durante o processo de cravação de uma estaca, a energia proveniente do martelo é transmitida à estaca pelos impactos deste sobre a mesma. A parcela dessa energia que é transmitida à estaca provoca deformações elásticas e plásticas em toda a massa de solo que se encontra envolvendo a estaca. O deslocamento máximo de uma estaca corresponde à soma da penetração permanente da estaca ao final de um golpe (nega) com o deslocamento de uma seção da estaca originada a partir de um impacto dinâmico (repique elástico).

De acordo com os resultados, quanto maior a energia, maior é o deslocamento máximo (Fig. 3). Observa-se que para as duas madeiras, quando aplicadas energias potenciais menores, a amplitude dos deslocamentos é pequena. Quando comparadas as duas madeiras, os maiores valores são para o coxim de Jatobá. Sob a perspectiva do peso do martelo, à medida que a mesma aumenta, aumenta-se o valor do deslocamento. Também se percebe que a altura de queda tem grande influência para os dados coletados. 


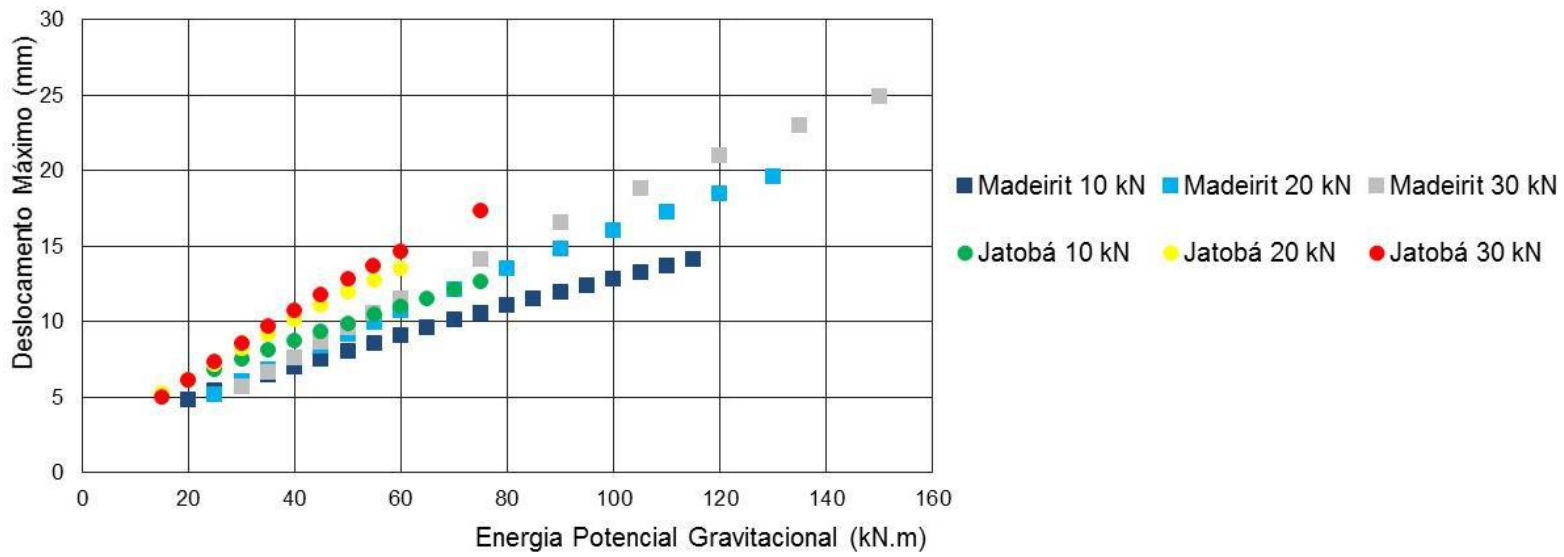

Figura 3: Deslocamento máximo vs. Energia Potencial

A eficiência do sistema de cravação é medida através do quociente entre a energia real que chega ao topo da estaca e a energia potencial. Conceitualmente, ao igualar as duas energias, têm-se o sistema perfeito. Porém, esta teoria é inalcançável, já que ocorrem perdas como o atrito com o equipamento e perdas devido o sistema de amortecimento após o impacto do bate-estacas. A eficiência pode ser considerada como a melhora do sistema de cravação de estacas.

Ao analisar os resultados da eficiência do coxim de Madeirit cravado com martelo de $10 \mathrm{kN}$, fica evidente o baixo desempenho alcançado, quando comparado com os demais (Fig. 4). Os valores obtidos pelo coxim de Jatobá com o martelo de $10 \mathrm{kN}$, apesar de maiores do que o de Madeirit, também estão baixos se comparados com os demais valores desta mesma madeira. Os resultados apontam uma tendência de aumento na eficiência do sistema quando se utiliza menores alturas de queda e maiores massas do sistema de cravação. Concluindo, o coxim de Jatobá apresenta os melhores valores de eficiência quando comparados com o coxim de Madeirit.

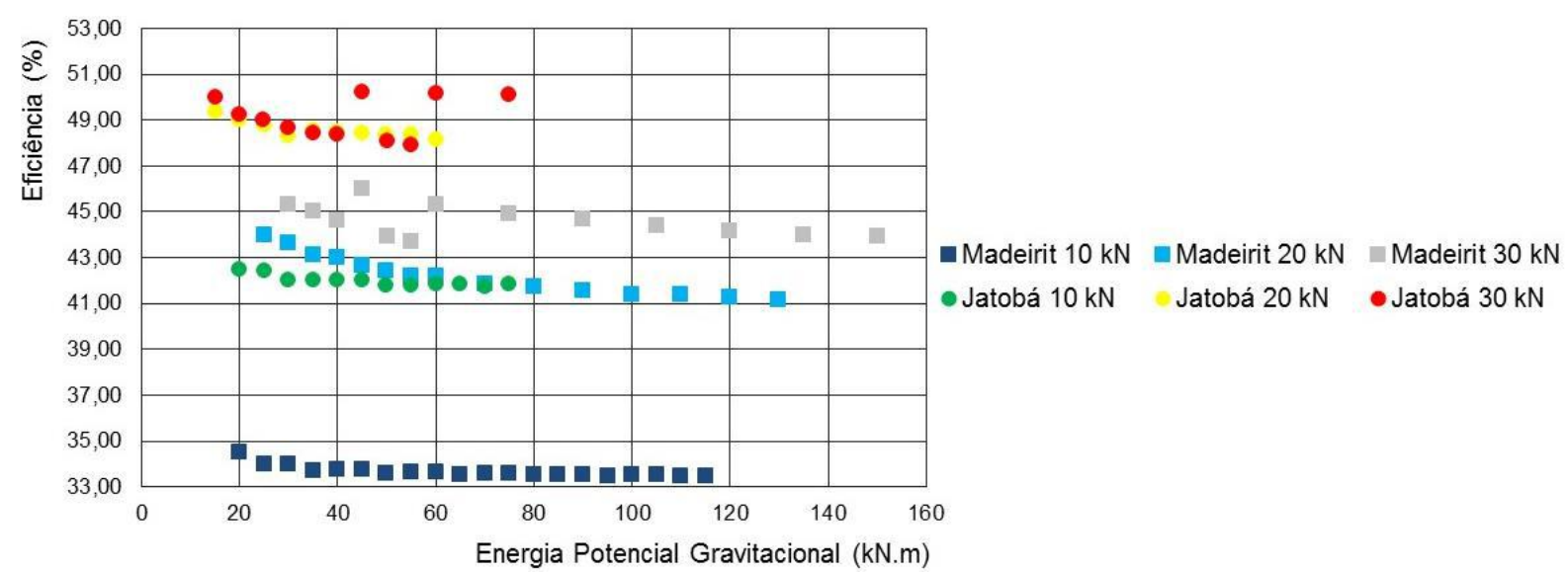

Figura 4: Eficiência vs. Energia Potencial

Num processo de cravação, a estaca está sujeita a um carregamento dinâmico axial, que é provocado pelo impacto, sobre a cabeça da estaca, de um martelo de massa previamente determinada, caindo de uma altura preestabelecida. Tal impacto gera uma onda de compressão descendente, que se propaga em direção a ponta, mantendo uma proporcionalidade entre os sinais registrados de força e velocidade das partículas no trecho livre da estaca. A existência de emendas na estaca, o atrito 
lateral entre ela e o solo, a resistência de ponta e até a qualidade dos materiais que a constituem, acabam provocando reflexões parciais da onda de impacto, ocasionando ondas ascendentes.

Os valores de força e velocidade fornecidos pelo relatório de simulação corresponde aos registros medidos numa seção na cabeça da estaca, durante a passagem da onda de tensão. Estes registros são usualmente apresentados juntos, tomando-se como referência inicial da escala de tempo o instante em que a onda descendente passa pelo topo da estaca, onde estão sendo medidos tais valores. A velocidade pode ser entendida como a velocidade com que uma partícula se move quando a onda se propaga. As curvas de força e velocidade mantém a proporcionalidade através da impedância até que comecem a chegar os primeiros sinais de ondas refletidas geradas pelo atrito lateral. Estas ondas de compressão aumentam a força na cabeça da estaca e diminuem a velocidade.

Assim, ao simular o comportamento da estaca no momento da cravação em função do tempo, é possível representar graficamente o comportamento da onda de choque da estaca no momento de sua cravação. Para isso, foram extraídos dados para cada conjunto martelo-madeira, considerando uma mesma energia potencial gravitacional. Ou seja, variou-se a altura de queda para todos os pesos de martelos (e para as duas madeiras) de tal modo que se obtivesse energias de cravação de $10 \mathrm{~kJ}$ até $60 \mathrm{~kJ}$, com intervalo entre elas de 5 em $5 \mathrm{~kJ}$.

Comparando os dados de força máxima entre martelos (Fig. 5 (a) e (b)), percebe-se que são muito próximos, com pouca variação. Apesar disso, pode-se dizer que a tendência é que os valores de força se tornem mais próximos (entre diferentes energias) com o aumento da massa do martelo. Percebe-se também que quanto maior o peso do martelo maior a amplitude do tempo para se atingir a força máxima.

Para os dados de velocidade, sob a comparação entre os pesos dos martelos utilizados (Fig. 5 (c) e (d)), percebe-se que, à medida que se aumenta a massa do sistema de cravação, aumenta-se a amplitude do tempo para atingir os valores das velocidades. Os resultados apontam que o coxim de Madeirit tem uma maior amplitude de tempo para atingir os valores de força e velocidade quando comparado ao Jatobá. Pode-se perceber também, que os valores encontrados de velocidade são muito próximos um do outro, quando comparado para os diferentes pesos de martelo e para a mesma madeira. 
(a) Força - Jatobá

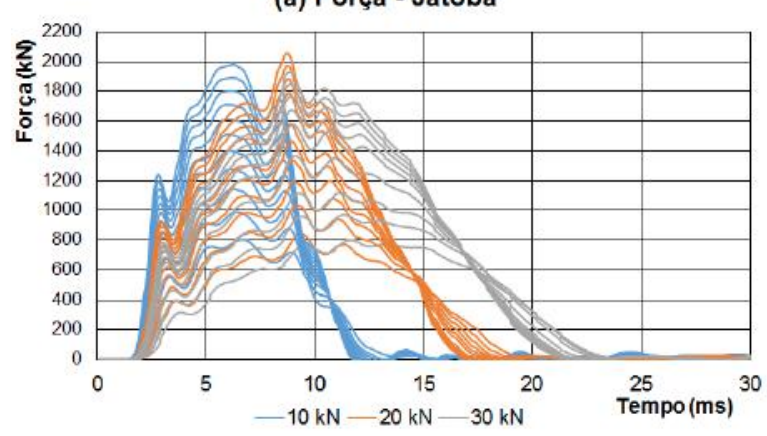

(c) Velocidade - Jatobá

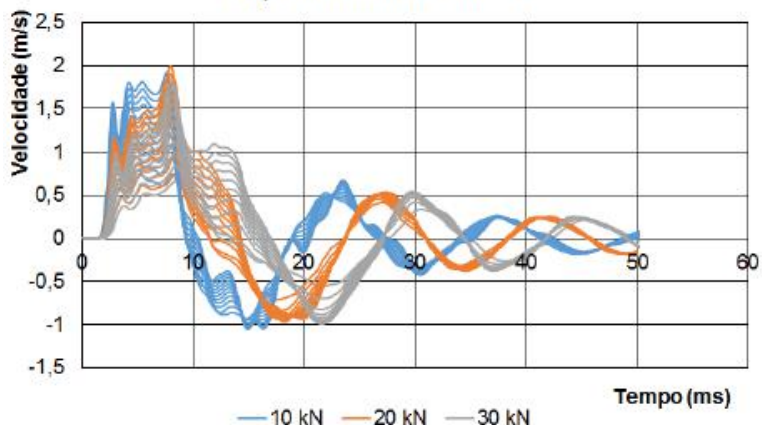

(b) Força - Madeirit

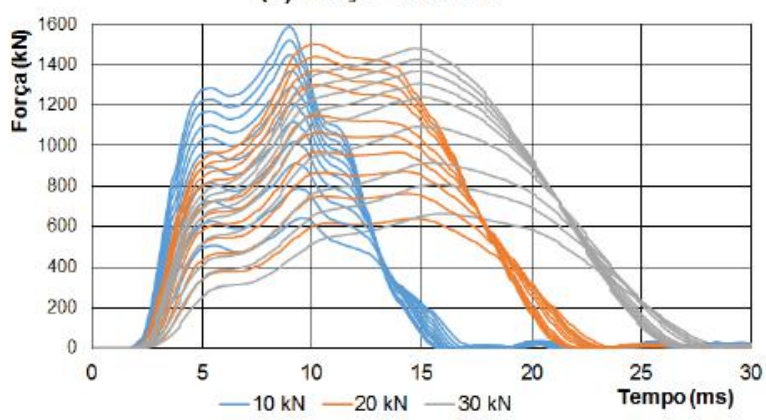

(d) Velocidade - Madeirit

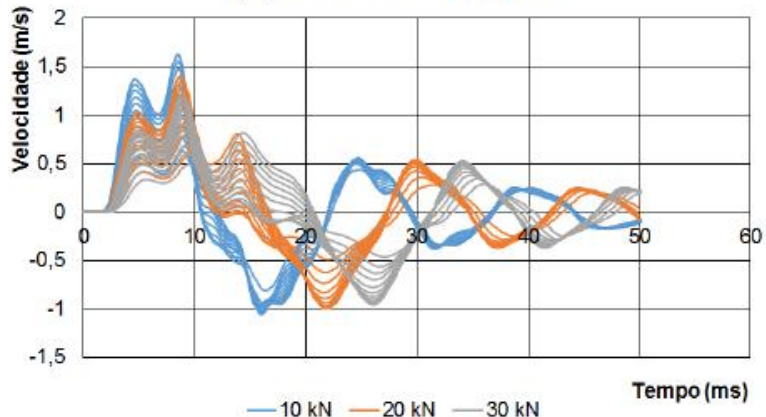

Figura 5: Comparativo entre os martelos. (a) Gráfico de força com Jatobá. (b) Gráfico de força com Madeirit. (c) Gráfico de velocidade com Jatobá. (d) Gráfico de velocidade com Madeirit.

Os valores máximos de força (em $\mathrm{kN}$ ) e velocidade (em $\mathrm{m} / \mathrm{s}$ ) para cada conjunto energia-martelo-madeira foram coletados, juntamente com as informações a respeito da amplitude dos valores máximos (intervalo de tempo de propagação da onda correspondente aos valores máximos), medidos em ms (mili segundos), para elaboração dos gráficos apresentados a seguir (Fig. 6).

Nos resultados obtidos para a força máxima (Fig. 6 (a)), percebeu-se que para todos os martelos, o coxim de Jatobá foi o que obteve os maiores valores, quando comparado ao Madeirit. Além disso, observou-se que conforme se aumenta a altura de queda, maior será a força máxima. Já para o gráfico que representa a amplitude da força (Fig. 6 (b)), percebeu-se que os menores valores são para o Jatobá. Ou seja, para o Madeirit o intervalo de tempo é maior para atingir a força máxima, em relação ao coxim de Jatobá.

Em relação aos gráficos da velocidade máxima (Fig. 6 (c)), observa-se que para todos os casos o coxim de Jatobá obteve os maiores valores, quando comparado ao coxim de Madeirit. Porém, observa-se que os valores encontrados de velocidade máxima para as duas madeiras ficaram bem próximos. Na análise da amplitude da velocidade máxima (Fig. 6 (d)), percebe-se que para o Jatobá foram registrados os menores intervalos de tempo, em relação ao coxim de Madeirit. Pode-se afirmar também, que o intervalo de tempo para atingir a velocidade máxima é diretamente proporcional a massa do martelo, pois a amplitude é maior para martelos de maior massa, para as duas madeiras. 
(a) Forças máximas

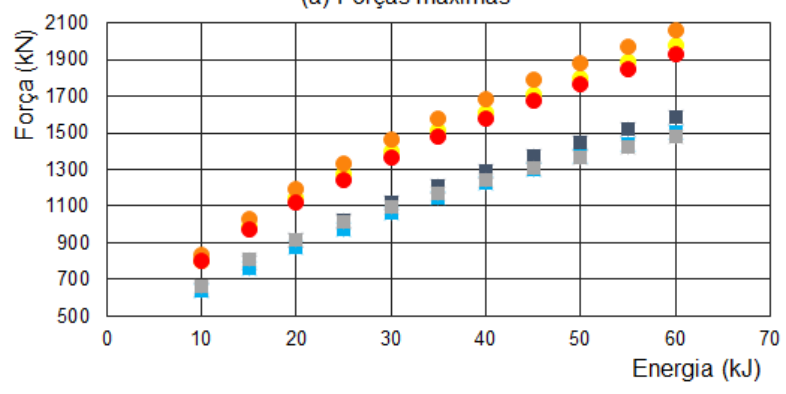

(c) Velocidades máximas

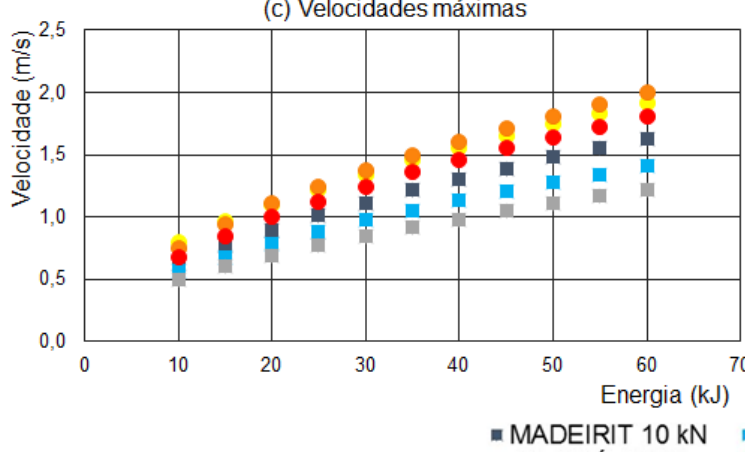

- MADEIRIT $10 \mathrm{kN}$

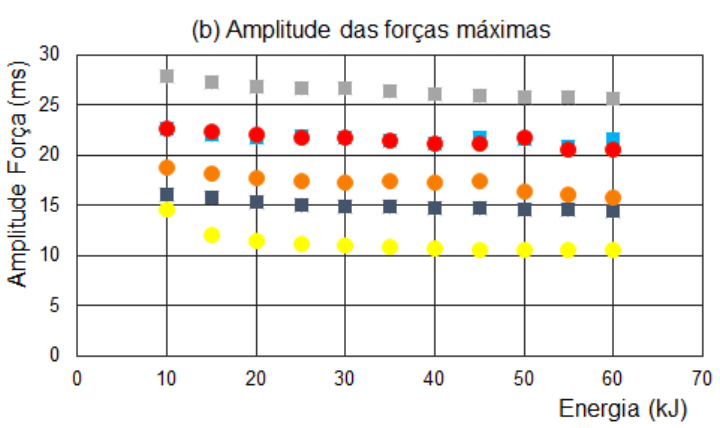

(d) Amplitude - Velocidades máximas

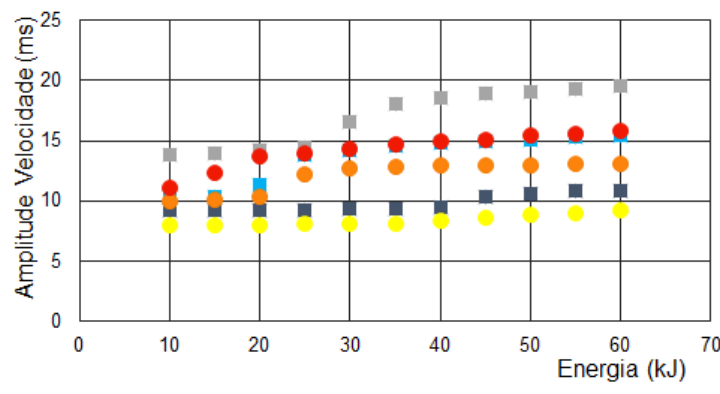

Figura 6: Valores máximos de força e velocidade vs. Energia. (a) Forças máximas.

(b) Amplitude das forças máximas. (c) Velocidades máximas. (d) Amplitude das velocidades máximas.

\section{Conclusões}

Dos resultados obtidos, observou-se que os valores de tensão de compressão máxima, nega e deslocamento máximo, aumentam com a altura de queda e o peso do martelo, sendo os maiores valores para o coxim de Jatobá.

Para uma mesma energia dispendida na cravação, os coxins de Jatobá obtiveram os maiores valores de força e velocidade, com uma menor amplitude em relação ao coxim de Madeirit.

Se observar da perspectiva das tensões produzidas, os melhores resultados são obtidos para a madeira que produz os menores valores. Para a tensão de compressão, os menores valores são para o coxim de Madeirit, porém a diferença dos valores de compressão entre as duas madeiras utilizadas é pequena. Em relação à tensão de tração, os menores valores encontrados são para o coxim de Jatobá. Vale destacar que as tensões de tração são as mais preocupantes já que a estaca, por ser de concreto, apresenta baixa resistência à essa solicitação.

Se confrontados os valores de diferentes pesos de martelos na análise do número de golpes, compressão, tração e eficiência, observamos que para ambas as madeiras os melhores resultados são encontrados para alturas de queda menores com martelos de maior massa. Assim, observou-se que, com a mesma energia, martelos mais pesados com alturas de queda menores são mais eficientes.

De todas as análises e estudos realizados em relação à cravação, o coxim de Jatobá resultou no menor número de golpes. Porém, conduz a um menor espectro de energia, pois a estaca quebra com mais facilidade e para alturas de queda inferiores 
ao coxim de Madeirit. Já para o coxim de Madeirit é necessária uma maior energia potencial para a cravação da mesma, ou seja, uma maior altura de queda.

Observou-se ainda que, com a mesma energia, martelos mais pesados com alturas de queda menores são mais eficientes, pois geram um menor número de golpes, menores tensões de compressão e tração, além de maior eficiência do conjunto.

A otimização do sistema de cravação, através do menor número de golpes totais sem promover a quebra da estaca, é uma maneira de se aplicar a profilaxia nas construções. Ao se evitarem manifestações patológicas como trincas e fissuras, que eventualmente aparecem na etapa de execução da fundação ou futuramente na superestrutura, colabora-se com a diminuição de gastos em possíveis medidas prognósticas e corretivas.

\section{Referências}

[1] Silva, F.B. (2011). Patologia das construções: Uma especialidade na engenharia civil. Téchne, edição 174, set. 2011. Disponível em: <http://techne.pini.com.br/ engenharia-civil/174/artigo285892-2.aspx>. Acesso em: 04 mar. 2017.

[2] Gonçalves, C.; Bernardes, G.P. de; Neves, L.F.S.(2009). Estacas pré-fabricadas de concreto: Quebras, Vibrações e ruídos. 1aㅡ Edição. São Paulo: Multpress.

[3] Gonçalves, C.; Bernardes, G.P. de; Neves, L.F.S.(2007). Estacas pré-fabricadas de concreto: teoria e prática, 1a Ed., São Paulo: Oficina de Textos.

[4] PDI (2002). GRLWEAPTM Wave equation analysis of pile driving: Procedures and models. Pile Dynamics, Inc. Cleveland.

[5] NBR 6122 (2010). Projeto e execução de fundações: procedimento. Associação Brasileira de Normas Técnicas - ABNT, Rio de Janeiro, Brasil.91 p.

[6] Santos, B.J. Estudo da cravabilidade de estacas pré-fabricadas de concreto. Trabalho de Conclusão de Curso. Curso de Engenharia Civil - Pontifícia Universidade Católica do Paraná, novembro de 2014.

[7] Paes, C.B. Cravabilidade de estacas: Análise do módulo de elasticidade da madeira do cepo. Trabalho de Conclusão de Curso. Curso de Engenharia Civil - Pontifícia Universidade Católica do Paraná, novembro de 2014. 